\section{Organic Bond Strengths and the Heat of Vaporization of Carbon}

Kinetic studies on several independent chemical reactions have led to a value of about $104 \mathrm{kcal}$. for the heat $X$ of removal of the first hydrogen from methane. Thus Trenner, Morikawa and H. S. Taylor ${ }^{1}$ obtained $108 \pm 5 \mathrm{kcal}$. from the reaction of deuterium atoms with methane, Patat ${ }^{2}$ a value of about $103 \mathrm{kcal}$. from the ortho-para hydrogen conversion by methyl radicals, and Rice and Dooley a value $100+6 \mathrm{kcal}$. from the thermal decomposition of methane at high temperatures. Butler and Polanyi ${ }^{4}$ have measured the velocity of the homogeneous thermal decomposition of alkyl iodides at low pressures, and their results, together with some thermo-chemical data, lead to the value $X=103 \cdot 6^{5}$.

From this value and the known heats of reaction, $2 \mathrm{CH}_{4} \rightarrow \mathrm{C}_{2} \mathrm{H}_{6}+\mathrm{H}_{2}$ and $\mathrm{H}_{2} \rightarrow 2 \mathrm{H}$, the $\mathrm{C}-\mathrm{C}$ bond strength in ethane is $88 \cdot 2^{5}$. (Rice and Johnstone ${ }^{6}$ from the concentration, at various temperatures, of free radicals in ethane obtained a value of about 80 kcal.)

In his recent book "The Nature of the Chemical Bond" Pauling has recommended an average bond strength for $\mathrm{C}-\mathrm{C}$ of $58.6 \mathrm{kcal}$. It is the object of this letter to point out this serious discrepancy and to suggest an explanation; the variations in bond energies established by Rossini ${ }^{8}$ are too small to account for it. Since Pauling's C-H bond strength $(87 \cdot 3)$ "is the value given by methane", that is, the average of the heats of the four successive hydrogenations of a carbon atom, a possible explanation is that the first $\mathrm{C}-\mathrm{H}$ bond broken in methane is considerably stronger than the others. This would lead to too low a value for the $\mathrm{C}-\mathrm{C}$ in ethane. Taking this first bond strength as 104 and assuming Pauling's average value, the average of the other three $\mathrm{C}-\mathrm{H}$ bonds would be only $82 \mathrm{kcal}$. Two arguments oppose this interpretation: (1) Voge $\theta^{\circ}$ has calculated the energies of these successive reactions approximately by quantum mechanics and obtained no such large differences. (2) The heat of successive substitution of the hydrogens in methane by a halogen varies but little along the series given by each halogen. Thus from the data for the heats of formation of the appropriate compounds given by Bichowsky and Rossini ${ }^{10}$, these substitution heats are (for the processes $\mathrm{CH}_{4}+\mathrm{Hal} . \rightarrow \mathrm{CH}_{3} \mathrm{Hal}$. $+\mathrm{H}, \mathrm{CH}_{3} \mathrm{Hal}$. + Hal. $\rightarrow \mathrm{CH}_{2} \mathrm{Hal}_{.2}+\mathrm{H}$, . . . etc.) : for substitution by $\mathrm{Cl},-21 \cdot 1,-21 \cdot 4,-21 \cdot 1,-20 \cdot 7$, by $\mathrm{Br},-35 \cdot 0$, $-32 \cdot 5,-32 \cdot 0,-31 \cdot 0$, by I, $-49 \cdot 0,-46 \cdot 8$, $-45 \cdot 3$ (fourth step unknown). It is difficult to see how such constancy for all three halogens is compatible with a large variation in the $\mathrm{C}-\mathrm{H}$ bond strengths.

If, therefore, this hypothesis is excluded, Pauling's table of carbon bond strengths must embody some systematic error. The obvious possibility is uncertainty in the heat of formation $V$ of carbon, as monatomic vapour, from carbon in the standard state (graphite or diamond). Two methods exist for the determination of $V:(a)$ the spectroscopically observed dissociation energy of carbon monoxide can be related to it by known combustion heats ; (b) by observation of the vapour pressure of graphite. Goldfinger and Jeunehomme ${ }^{11}$ have considered that method (a) leaves three values possible: - 168.8, $-123 \cdot 6$, and $-107 \mathrm{keal}$. They calculated the vapour pressures corresponding to each and compared these calculations with experiment. Their results show that the lowest value is very improbable, but, although the most modern and accurate determinations agree best with the highest of these three values, they adopt $V=-123 \cdot 6$, the value recommended from considerations of spectra by Herzberg ${ }^{12}$. As Herzberg pointed out, the vibrational levels are insufficiently known for a Birge-Sponer extrapolation, so that the evidence for $V$ depends on the interpretation of certain predissociation limits and the assumption that these are not 'accidental' ; moreover, Schmid and Gerö ${ }^{13}$ have considered these data as supporting a value of $V$ of only $73 \mathrm{kcal}$., which is on chemical grounds very unlikely. The spectroscopic results are not, therefore, unequivocal, while the high value 168.8 is supported by some calculations (of which the details were not given) by Penney ${ }^{14}$, who obtained $V=170$, "a value unlikely to be in error by more than $10 \% "$.

Now it can be shown that in these average bond strength systems, if $V$ is too low by $x$, the $\mathrm{C}-\mathrm{H}$. value will be too low by $\frac{1}{4} x$, the $\mathrm{C}-\mathrm{C}$ by $\frac{1}{2} x$, and the $\mathrm{C}=\mathrm{C}$ by $x$. If we take the high value $168 \cdot 8$ for $V$, Pauling's $\mathrm{C}-\mathrm{H}$ of 87.3 becomes 98.6 , his $\mathrm{C}-\mathrm{C}$ of 58.6 becomes $81 \cdot 2$, and his $\mathrm{C}=\mathrm{C}$ of 100 becomes 145 . A similar correction to the 'average' bond strengths of Sidgwick $^{15}$, who took $V=150$, gives for the aliphatic series $\mathrm{C}-\mathrm{H} 98 \cdot 4, \mathrm{C}-\mathrm{C} 81 \cdot 1, \mathrm{C}=\mathrm{C} 143$. These corrected values agree, to within the uncertainty inherent in 'average' bond strengths, with those derived from consideration of the decomposition kinetics of alkyl iodides ${ }^{4,5}$.

The single assumption, therefore, that the heat of vaporization of graphite to monatomic carbon vapour is 168.8 or thereabouts is sufficient to reconcile the serious discrepancies between 'kinetic' and 'thermochemical' values for carbon bond strengths. In view of this fact, it would be of interest if further spectroscopic research could give a definitive answer to this question of the heat of dissociation of carbon monoxide.

E. C. BAUGHAN.

Chemistry Department,

University, Manchester. March 28

${ }^{1}$ Trenner, Morikawa and Tayko, H. S., J. Chem. Phys., 5, 203 (1937).

- Patat, Z. phys. Chem., 32B, 274 (1936).

${ }^{3}$ Rice, F. O., and Dooley, J. Amer. Chem. Soc., 56, 2747 (1934).

- Butler and Polanyi, NATURe, 146, 129 (1940).

s Baughan and Polanyi, Nature, 146, 685 (1940).

- Rice, F. O., and Johnstone, J. Amer. Chem. Soc., 56, 488 (1934).

"Pauling, "The Nature of the Chemical Bond" (Cornell University Press, 1939).

B Rossini, Ind. Eng. Chem., 29, 1424 (1937).

- Voge, J. Chem. Phys., 4, 581 (1936).

${ }^{10}$ Bichowsky and Rossini, "The Thermochemistry of the Chemical Substances" (New York : Reinhold, 1936).

${ }^{11}$ Goldfinger and Jeunehomme, Trans. Far. Soc., 32, 1591 (1936).

${ }_{12}$ Herzberg, Chem. Rev., 20, 145 (1937).

${ }^{13}$ Schmid and Gerö, $Z$. phy8. Chem., 38B, 105 (1937).

14 Penney, Trans. Far. Soc., 35, 835 (1939).

1s Sidgwick, "The Covalent Link in Chemistry" (Cornell University Press, 1933), chap. iv, 1933.

\section{Use of Silver Nitrate for the Histochemical Demonstration of Ascorbic Acid}

SILver nitrate in acid solution has been widely used for the study of the distribution of ascorbic acid in tissues and cells ${ }^{1}$. A survey has recently been made, using this method, of its occurrence in chick embryos $^{2}$. During this study a previously unreported phenomenon was observed in newly calcified bone : this was a heavy dark deposit which filled many of the newly formed trabeculæ of cartilage and mem- 